\title{
Poupança Florestal: a case of rural sustainable development
}

\author{
S. A. P. Esteves ${ }^{1}$, R. Mazon ${ }^{2}$, F. C. Pereira ${ }^{3}$ \& M. Jerozolimski ${ }^{3}$ \\ ${ }^{I}$ Fundação Getúlio Vargas, SP, Brasil \\ ${ }^{2}$ Universidade Ibirapuera, SP, Brasil \\ ${ }^{3}$ AMCE Negócios Sustentáveis, SP, Brasil
}

\begin{abstract}
In the current debate on creating value for organizations and society to consider the outlook of sustainability in terms of good business governance, three aspects have been constantly brought up: the results from the action of different actors measured in economic, social, environmental and cultural perspectives; the influence of the action of these actors in promoting human rights; and the quality of their contribution, individual and collectively, for sustainable development. This case study takes into consideration the aforementioned aspects as guidelines in a preliminary study to the contribution of a forest venture program to rural sustainable development. The study was based on data of 33 representatives of 13 interest groups involved in the program in eight selected municipalities in a universe of 23 in which the program has been implemented. Furthermore, secondary sources were used to obtain an even deeper understanding of the perspectives of the actors. A case study methodology was used in accordance with Yin (Estudo de caso. 3 ed. 2005, p.212), and the results were analyzed based on Bauer and Gaskell (Pesquisa qualitativa com texto, imagem e som: un manual práctico. 2 ed. 2002, p516.).

Key words: sustainability, sustainable development, rural development, forestry activities, rural and urban relationships and stakeholder's management.
\end{abstract}

\section{Introduction}

This article analyzes a forest venture program from the specific point of view of sustainability, involving aspects of creating value for different actors, managing impacts, promotion of human rights and contribution to sustainable development. In preparing this text primary sources were used (interviews and conversations in 
depth with the main actors implicated in the program) and secondary sources (materials published about the program, materials on the competitive scenario in the field of pulp and paper, and on the environment in which the program is implemented.)

The object of this study is the program of the Brazilian company Votorantim Celulose e Papel - VCP - www.vcp.com.br, as it has being adopted in southern Brazil. In general terms the program motivates land owners to plant eucalyptus for pulp and paper mills. The dynamic of the program is established based on standard contracts between VCP and land owners with a guarantee to purchase the trees. Due to economic, social, environmental and cultural questions it addresses, the program implies numerous stakeholders - the company, the financial agent, the community, NGO's and civil associations, academia, research groups, government agencies, the public prosecutor's office (related to civil and environmental matters), social and environmental movements which represent different roles and interests. Therefore, a new and complex dynamics in the relations between the urban and rural society in the region, on bringing together actors with different viewpoints, outlooks and commitments and little experience in interrelating among themselves, is introduced by this VCP's program.

In the debate on the nature of the engagement of interested parties who meet with specific opportunities and objectives in mind, this article seeks to delineate the general guidelines to, simultaneously, optimizing returns for the actors involved, promoting human rights and offering an objective contribution to the sustainable development of the region. Is there a feasible and legitimated operative process that considers the different interests involved and creates a willingness to intentionally participate in the local sustainable development, stressing social dialogues for inclusion, cooperation and the search for synergies among the actors? Or are the actors betting on operative models that become feasible through articulate monologues, circumstantial tradeoffs and bargaining or agreements that seek to obtain specific returns without an explicit commitment to any development effort? This question assumes strategic relevance in the current competitive scenario, not only for companies but also for society as a whole. In global scenarios, the sense of a joint competitive effort, more than the individual competitive actors themselves, makes the question of cooperation and production arrangements a central theme in the debate on the nature of engagement of the interested parties for the value creation which implies a pragmatic contribution in sustainable development.

From the point of view of recognizing the shared responsibility in the economic, social, environmental and cultural impacts resulting from a complementary or individual action of the different actors, the study considers, as much as possible, but without limiting itself to, traditionally accepted concepts. It incorporates the discourse, the reports on actions taken or to be taken, and the capacity of articulation of the different actors, not only as indicators of the generation of impacts, but also as factors which can create or destroy value that affects the returns from the program and its contribution to local and regional development. Generally speaking, the discourses of the 
different actors represent their perception of the questions proposed by the protocols of research and are not backed by quantitative data.

Another important aspect of the study are the questions involving human rights, especially in the scope foreseen in the Conventions of the International Labor Organization regarding specifically child labor (ILO [1]). These questions will be examined specially against a background of small and medium sized farmers who try to make the forestry program viable or even maximize their returns from the undertaking.

From the point of view of the capacity of the program in creating value for the actors involved, the study examined its results in the light of the interests of each actor. These interests are expressed in exercising their role and take the actions to make the program feasible. To the degree in which the parties get involved only for their exclusive interests, without an explicit commitment to the circumambient environment, the contribution of the different actors in terms of sustainable development is only relative.

Finally the article points out the limits of contribution of the program for developing forests in the light of a local and regional development effort. The assumption adopted is that the economic, social, environmental, cultural and governmental agents - regardless of the production arrangement in which they are involved - have a shared responsibility in the effort of local development, which, in the end, reverts in benefit for themselves and the community where they are located. The recognition of the shared role may create a strategic intent capable of making the partnership in the program become a true vector of development. Furthermore, the connection of the program with other initiatives in the region will probably generate potentially more positive returns and reduce the ceticism over the program's potential to generate development.

\section{Object of the study and framework of analysis}

To preliminary study the contribution of these forestry activities in terms of rural sustainable development, one program and one region where it is being implemented were selected. To this end a series of research protocols were prepared which were applied to the different actors involved in the program.

To understand their involvement in the program, we classified these actors in three categories, using the following criteria:

a. Actors, institutions or not, who have clear interests involved, and expect well defined returns regarding the program and play a relevant role in its implementation. They are: the company, the financial agent and the rural producer or farmer.

b. Actors who in some way or another are impacted by the program regarding the commitments assumed by them with their public. They include: social movements, environmentalists, formal community representatives and formal representatives of business sector.

c. Actors who contribute to the program providing guidance, guidelines, and technical and scientific support, but maintain a certain distance 
from the principal questions implied in its implementation. They include EMATER, the Ministry of the Environment and academia.

These groups of actors are represented in Figure 1. The relative positioning and the distance between them suggest the intensity of relations.

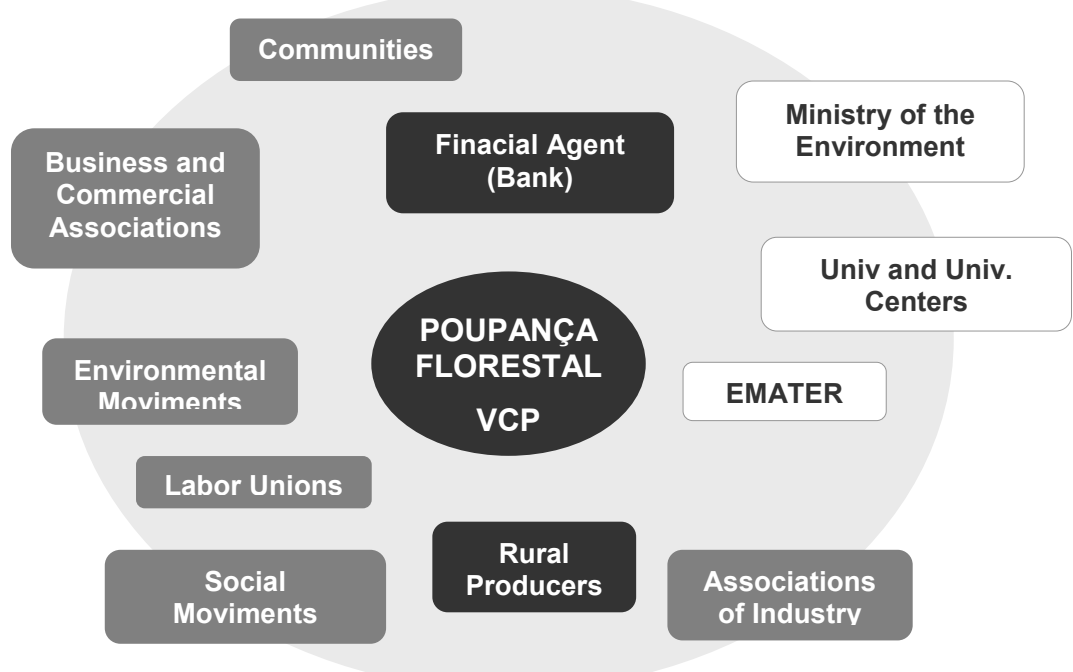

Figure 1: Chart of the actors.

The structuring of protocols, the field work and the data analysis were based on four guidelines, considered by the authors in this preliminary study, sufficient to preliminary understand the contribution of the program to rural sustainable development.

- The capacity to create economic, social, environmental and cultural value;

- The existence of economic, social, environmental and cultural impacts resulting from the activities of these actors;

- Child labor questions specially when small economic agents with scarce resources are involved,

- The objective contribution to sustainable development.

\section{Methodology and results}

This case study was developed based on the methodology proposed by Yin [2], and the primary research was based on protocols differentiated for each actor, although bearing a common line of investigation in common (the four guidelines) so that some correlations among them were possible. Each actor, however, could expand or provide in-depth information, on responding to the questions in the protocols. 
The Poupança Florestal program was implemented by September 2006, in 23 municipalities (Figure 2) located in the southern half of the state of Rio Grande do Sul. In the region of Pelotas are the municipalities of Amaral Ferrador, Arroio Grande, Canguçu, Capão do Leão, Cerrito, Cristal, Herval, Jaguarão, Pedras Altas, Pedro Osório, the municipality of Pelotas itself, Pinheiro Machado, Piratini, Rio Grande, Santa Vitória do Palmar, Santana da Boa Vista, São Lourenço do Sul. In the region of Bagé are the municipalities of Aceguá, Bagé Caçapava do Sul, Candiota, Hulha Negra, and Lavras do Sul.

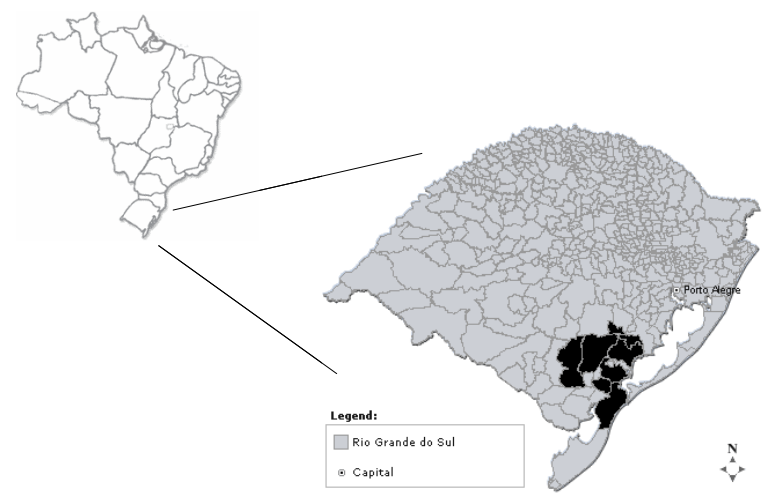

Figure 2: Location of the program.

Considering that it would not be financially feasible to cover the 23 municipalities where the program was implemented at the time of this study, a sample of this universe was chosen. To define this sample, the municipalities were grouped in three different categories, in accordance with the HDI-M (Index of Human Development- per Municipality), corresponding to the 2000 census of the Brazilian Institute of Geography and Statistics (PNUD [3]):

- Group A -Municipalities: HDI-M greater than 0.78

- Group B -Municipalities: HDI-M between 0.75 and 0.78

- Group C-Municipalities: HDI-M less than 0.75

The HDI-M is an index disclosed every year by the Program of the United Nations for Development with the function of alternatively analyzing development within a perspective different from the one provided by the Gross Domestic Product (GDP). The HDI-M is based on the supposition that, in order to quantify the advance in terms of development, one should not consider only the economic aspects, but also social, cultural and political references that influence the quality of human life. In the HDI-M, three sub-indices are considered, and are aimed at educational analysis (HDI-E), revenue or income analysis (HDI-I) and longevity index (HDI-L) of a population.

Taking as reference some secondary research, eight municipalities were selected to be visited during the field work, obeying a certain degree of 
proportionality among these HDI-M groups, and considering also their geographic locations and access conditions. The research protocols were applied in two municipalities of Group A (40\% of the total), four of Group B (33\% of the total), two of Group C (50\% of the total)), respectively: Pelotas, Rio Grande, São Lourenço do Sul, Capão do Leão, Piratini, Cristal, Canguçu and Amaral Ferrador (Figure 3).

\begin{tabular}{|c|c|c|c|c|c|}
\hline \multicolumn{6}{|c|}{ CLASSIFICATION OF MUNICIPALITIES: POUPANÇA FLORESTAL - RS } \\
\hline Municipality & Classification & Est. Population & $\begin{array}{c}\text { Area } \\
(\mathrm{Km} 2)\end{array}$ & Current GDP (R\$) & $\begin{array}{c}\text { HDI-M, } \\
2000\end{array}$ \\
\hline Pelotas & $\mathbf{A}$ & 342513 & 1609 & $\$ 1,897,411.00$ & 0.816 \\
\hline Rio Grande & $\mathbf{A}$ & 195392 & 2814 & $\$ 2,386,709.00$ & 0.793 \\
\hline São Lourenço do Sul & B & 45210 & 2036 & $258,240.00$ & 0.777 \\
\hline Capão do Leão & B & 26740 & 785 & $175,402.00$ & 0.77 \\
\hline Piratini & B & 20518 & 3561 & $101,096.00$ & 0.756 \\
\hline Cristal & B & 6981 & 682 & $42,652.00$ & 0.755 \\
\hline Canguçu & C & 52124 & 3525 & $271,901.00$ & 0.743 \\
\hline Amaral Ferrador & $\mathrm{C}$ & 5629 & 506 & $29,372.00$ & 0.727 \\
\hline
\end{tabular}

Sources: IBGE 2005/`PNUMA.

Figure 3: $\quad$ HDI-M of municipalities in sample.

Respecting these criteria, 29 local interviews were held, as well as two digital interviews with the Ministry of the Environment and Farsul, and two in São Paulo - the company and the financial agent, to expand some information.

According to Bauer and Gaskell [4] the research process in the present study could be classified as soft, since it avoids numbers, dealing with interpretations of social realities through in-depth interviews. The data collected were analyzed and consolidated based on four guidelines adopted and in the references of Bauer and Gaskell (Bauer \& Gaskell [4]), which made it possible to visualize the dynamics of the relations among all the actors. .

\section{Discussion}

The results of the primary and secondary research were analyzed in accordance with the proposed framework, based on the four guidelines and in the declared activities and actions of the groups of identified actors. As references, the classic definition of Sustainable Development was used: that which meets the needs of the present without compromising future generations (World Commission on the Environment) [6], and a concept of sustainability with which the authors have been working. This concept implies that sustainability requires the notion of a broaden space of dialogue to be taken into consideration in which different interests can assume their best possibilities, including a pragmatic contribution to sustainable development.

Composing one important part of the analysis, the research protocols propose to observe the actors with regard to job and income generation. The perception, based on the results of the interviews, generally speaking, is that the program is a generator of employment and income. It is important to consider that the gamut of opportunities in the region is very small. Therefore, some aspects need to be 
stressed. The first is the question of a formal or informal work relationship, which implies the existence, or not, of labour rights. Findings of this research indicate that in some stages of rural work, especially related to cutting down weeds, bushes and planting the trees, an informal work relationship is characterized, without any legal employer-employee relationship. Another aspect is the question of temporary employment. Some of the interviewees affirm, "The generation of employment and income occurs only in the short term, during the planting of the saplings." "The program generates employment for persons in the region, however it is just temporary."

In the realm of possibilities, the interviews with some actors propose a debate on the need to consider job and income generation promoted by the program against other potential economic possibilities of the region in terms of family agriculture, agrarian reform, tourism, fishing and, in some locations, port activities. These actors mention the need of a development plan for the region with the creation of a greater gamut of opportunities. Without this diversity of opportunities, they suggest, the conditions for breaking the cycle of poverty for coming generations are very weak. These lack of opportunities becomes evident in statements like: "The program provides an economic alternative in the midst of the impoverishment of the southern half of the state of Rio Grande do Sul which is occurring gradually." Another interviewee: "The situation of poverty in the region causes the inhabitants to be interested in any new economic alternative that is being made available."

Furthermore from the economic point of view, the analysis of the research data and the secondary documentation suggest that three other aspects should be considered: the increase of revenues of the municipalities, the increased value of the land, and the economic impact on local trade, despite the fact that the large quantities of materials are not purchased in the region, since the program follows a global practice of centralized purchases to seek economies of scale.

The field work and the contact with different agents point further to some important aspects, even though the main concern expressed in the interviews is the generation of employment and income. Like in any situation of change where future scenarios are not very clear, various persons interviewed were worried about the change in the economic matrix of the region and in the cultural profile of the farm worker with the consequent disappearance of other farm crops.

There are various questions that arisen from analyzing the interviews and from the examination of secondary sources that should be examined: at what extension will the program be able, even not connected with other initiatives to promote development, improve the local conditions of life? Will the small and medium farmers, in a long term, become dependent on large corporations? Are there incompatibilities between the proposal of the program and other ways to develop family agriculture in the region, compatibles with its historical vocation? Can one consider that the program, on stimulating forestry, affects in a bad way the local traditions related to farming and animal raising in the region?

The concept of agricultural-forestry presented in the program consists of planting eucalyptus trees in more open spaces, sufficient for the circulation of machinery for preparing the soil, planting and harvesting grains, as well as 
making viable animal grazing. Some persons interviewed consider that agricultural-forestry is a mechanism capable of reducing dependence of the small farmer on large companies and motivating them to diversify their crops.

It is important to stress that the development program in the region was launched two years ago and this is insufficient time to make an in-depth analysis of some of its results and impacts.

With regard to human rights, the field work sought to identify aspects and vulnerabilities related to child labor. Based on the interviews, one may affirm that the program has no mechanisms to prevent child labor, especially among poorer farmers. This is an interesting point of view since the program has mechanisms for environmental protection officially expressed in the texts promoting adherence to it. Some persons interviewed assured that there is a possibility of child labor in some auxiliary farm work, such as: "There is a chance of child labor in some activities as cutting down the weeds and fighting ants." However, the majority of those interviewed did not believe the program would stimulate child labor, and some do not consider "simple chores" to represent child labor, as can be seen in the following interview. "Child labor is a controversial question regarding its concept. I believe that in a certain way, work is a manner to stimulate responsibility in the youth, when his study and his leisure activities are respected."

There is considerable controversy considering environmental questions in mono-culture areas, where only one crop is grown, especially eucalyptus. In the interviews there were as many positive as negative comments on this question. "The plantations preserve the areas of environmental protection, which are not being protected by local agriculture." "The forest functions as a mechanism of conservation in seriously degraded areas." "The rapid growth of eucalyptus and the high level of evaporation-transpiration will provoke a high level of consumption of water in the underground water level, contributing to desertification." Or "The Gaucho pampas is a bioma that is extremely diverse and monocultures cause a loss of biodiversity and an environmental imbalance." These points of view demonstrate the strong interests of different actors, which are also detailed in the documents analyzed in the secondary sources (Via Campesina [6]. Generally speaking, the actors that have more defined interests regarding the program tend to minimize the environmental questions, while those actors who represent a public with specific interests and specific viewpoints seek to maximize the negative aspects of these questions.

The main questions in debate, however, are related to the guarantee of the principle of precaution (studies of environmental impact for planting eucalyptus in the region), as well as the impacts associated with monoculture and the changes in the water cycle, the impacts on biodiversity, the preservation of native species, the creation of environmental protection areas, legal reserves and the change in the natural landscape.

The actors involved with social questions are those who wonder whether the program will in fact promote development. Their principal arguments involve the agrarian reform (will it be able to get people to remain on the farm and increase in a sustainable way the generation of jobs?). Other questions deal with the 
potential consequences of concentration of land in the hands of large companies, the concentration of income and the presumption that the profits will not be applied in the region. One argument, specially, from a secondary source, deserves to be highlighted. It proposes the need to promote the change the standards of consumption in society, with a reduction in the consumption of paper in general and white paper specifically, to minimize environmental impacts.

\section{Conclusions}

The program has a major influence in the region where it is being implanted in numerous aspects. The dynamics inherent in the way it is being operated influences the economy and the local culture, increases the debate over environmental questions and raises the question if this is in fact a contribution to sustainable development in the region.

The analysis of the data indicates that the contribution of the program for sustainable development is relative, being a species of sub-product in the search by the actors for results or specific benefits that interest only to them. There is no evidence of an intention of the actors in promoting sustainable development by means of a program of forestry development, although their discourse may seem to be articulated as pro-sustainable development. There is also no evidence of the intention in connecting the program in the future with other initiatives that have a potential to promote development.

There is evidence, however, that some questions related to the program will remain open, due the nature of the interests of the actors involved. This may be considered inherent to the process of development. Other questions, however, could be better addressed if the actors had invested more in social dialogues around their expectations and had recognized the need for an explicit commitment with sustainable development. For example, the questions involving temporary jobs could have been better settled if farm activities in a regional perspective were considered. A model of management that should take these aspects into consideration has a great potential of impacting positively on program returns. Supplementary studies, however, may address competitiveness questions related to the program when human rights and sustainable development integrates its expected returns.

\section{References}

[1] OIT. (WTO) International program for the eradication of child labor. IPEC. Available <http://www.oitbrasil.org.br/prgatv/in_focus/ipec/errad trabin.php> Accessed in June 2006.

[2] Yin, Robert. Estudo de caso: planejamento e métodos. 3. ed. Porto Alegre: Bookman, 2005. p.212.

[3] PNUD. Desenvolvimento humano e HDI. Available $<$ http://www.pnud.org.br/HDI/> Accessed in June, 2006. 
300 Sustainable Development and Planning III

[4] Bauer, Martin; Gaskell, George. Pesquisa qualitativa com texto, imagem e som: um manual prático. 2. ed. Petrópolis, RJ: Vozes, 2002. p.516.

[5] Comissão Mundial Sobre Meio Ambiente E Desenvolvimento Sustentável. Nosso futuro comum. Editora da Fundação Getúlio Vargas, 1988. p.430.

[6] Via Campesina. O Latifúndio dos Eucaliptos: Informações básicas sobre as monoculturas de árvores e a indústria de papel. Rio Grande do Sul. Pontocom. 2006. 